\title{
The Impact of Rice Production Technology Adoption in Fogera Woreda, South Gondar, Ethiopia
}

\author{
Getaye Gizaw, Oda Bultum University \\ Muhdin Mohamedhussen Batu, Kotebe Metropolitan University
}

\begin{abstract}
This study was designed to assess the impact of adoption of rice production technology on households' rice production in Fogera Woreda using cross sectional data obtained from 191 rice farmers selected from four kebeles to represent major rice producers. The study used propensity score matching to assess impact of adoption of rice production technology on household production levels. The result showed adoption of rice production technology has a robust and positive effect on farmers' rice production in quintal per hectare. The average treatment effect on the treated (ATT) was about 9.48 quintal yield per-hectare increase for adopters as compared to non-adopters. The result of sensitivity analysis also shows average treatment effect on treated is not sensitive to external change.
\end{abstract}

Keywords: Rice, Technology, Adoption, Impact, Production, Propensities Score Matching.

DOI: $10.7176 /$ ISDE/11-4-01

Publication date:August $31^{\text {st }} 2020$

\section{Background of the Study}

The study of how individuals are able to escape poverty is a central issue of economic development theory. Of the poor people worldwide (those who consume less than a 1 dollar-a-day), 75 per cent work and live in rural areas and projections suggest that over 60 percent will continue to do so up to 2025 (Mendola, 2007). These are good reasons to emphasize research on rural poverty reduction, and to redirect attention and expenditure towards agricultural development. Agricultural technology is among the most revolutionary and impactful areas of modern technology, driven by the fundamental need for food and for feeding an ever-growing population. It has opened an era in which powered machinery does the work formerly performed by people and animals (such as oxen and horses). These machines have massively increased farm output and dramatically changed the way people are employed and produce food worldwide. A well-known example of agricultural machinery is the tractor. Currently, mechanized agriculture also involves the use of airplanes and helicopters (FAO, 2010).

The agricultural technology and improved practices play a key role in increasing agricultural production (and hence improving national food security) in developing countries. Where successful, adoption of improved agricultural technology could stimulate overall economic growth through inter sectorial linkages while conserving natural resources (Abdulai, et al 2005). Given the close link between food insecurity, farming and environmental degradation the impact of cultivation practices has received significant attention in the last two decades. New cultivation techniques have been introduced in many countries to enhance production in the agriculture sector (Graaff, et al 2011). Accelerating agricultural growth in Ethiopia has wide-ranging impacts beyond smallholder farmers and rural development. In spite of its enormous agricultural potential, Ethiopia's history, however, is punctuated by food insecurity and famine due to climatic variability and the poor performance of the agricultural sector. In mindful of these problems, the government of Ethiopia launched policies and strategies that set out agriculture as a primary stimulus to generate increased output, employment, income and agricultural production.

Several adoption research findings have pointed to the fact that the use of new agricultural technology, such as high yielding varieties that kick-started the Green Revolution in Asia, could lead to significant increase in agricultural production in Africa and stimulate the transition from low production subsistence agriculture to a high production agro-industrial economy (World Bank, 2008). Scholars in the discipline argues that agricultural production growth will not be possible without developing and disseminating cost effective yield-increasing technology, since it is no longer possible to meet the needs of increasing numbers of people by expanding the area under cultivation or relying on irrigation.

Bola et al. (2012), used a local average treatment effect (LATE) method to examine the impact of improved agricultural technology adoption on rural farmers' welfare in Nigeria, using a cross sectional data of 481 rice producers stated that the decision of small farm households to adopt improved rice varieties were determined by the different socio-economic /demographic and institutional variables such as number of years of residence in the village, access to media, mobile phone, vocational training, livestock ownership, access to improved seed, and income from other crop production significantly increased the probability of adoption. As a result, adopters received more 3.6 quintals of rice additions per hectare.

Mendola (2007) used the Propensity Score Matching (PSM) to assess the impact of agricultural technology adoption on poverty in Bangladesh and observes that the adoption of high yielding improved varieties has a positive effect on household wellbeing in Bangladesh. In the same vein, Kijima, et al., (2008) conducted a study on the impact of New Rice for Africa (NERICA) in Uganda and found that NERICA adoption reduces poverty 
without deteriorating the income distribution. Diagne, et al., (2009) also assess the impact of NERICA adoption on rice yield in Cote d'Ivoire. The results show a positive and significant increase in yield particularly on the female farmers. More recently, Dontsop-Nguezet, et al (2011) also examined the impact of NERICA adoption on farmers' welfare in Nigeria. The result of the study shows that adoption of NERICA varieties has a positive and significant impact on farm household income and welfare measured by the per capita expenditure and poverty reduction in rural Nigeria.

A study by Adekambi et al, (2009) on the impact of agricultural technology adoption on poverty in Benin indicates the increase in production of rice farmers, following the adoption of NERICA (new rice in Africa) varieties. These results suggest that the promotion of NERICA cultivation can contribute to improving expenditure/income of farmers and consequently to poverty reduction. Studies conducted in Asia also reveal similar results. Using a propensity score matching method, Similarly, Wu et al (2010) conducted an impact study rural China and found that adoption of agricultural technology had a positive impact on farmers' well-being thereby improving household income.

In Ethiopia, despite the significance of rice in the livelihood of many farmers and households, it is only recently that few studies have been done on rice. Furthermore, its impacts on rice production have not yet been studied. Hence, this study was conducted to assess the impact of rice production technology adoption on rice production of the farming households using estimation techniques in Fogera woreda.

\section{Research Methodology}

Fogera woreda is one of the 106 woreda of Amhara national regional state and found in South Gondar zone. It is situated at $11^{0} 58$ latitudes and $37^{0} 41$ longitudes. The district is bordered on the south by Dera, on the west by Lake Tana, on the north by the Rib River which separates it from Kemkem, on the north east by Ebinat, and on the east by Farta.

In this study, both primary and secondary data sources were used. Both quantitative and qualitative data were gathered from different sources of the study area. A multi stage sampling procedure was used to select the kebeles and sample households. In the first stage, four kebeles were selected purposively from 15 rice producing kebeles based on their agro ecological zone. In the second stage after lists of farmers were obtained from the district Agricultural and rural development office, farmers who were cultivating rice in four kebeles, 91 adopter sample household heads were taken as respondent using probability proportional to size. 100 non-adopter respondents were selected using simple random sampling method based on their proportion. The data was collected from December 2017 up to April 2017 for five months.

Binary logistic regression was incorporated to analyze relationships between a dichotomous dependent variable and independent variables.

The function form of model is specified as follows: -

$\mathrm{P}=\mathrm{E}(\mathrm{Y}=1 / X i)=\frac{1}{1+e^{-(B o+B i X i)}}$.

This will be writing as follows, $z_{i}$ is equal to $\mathrm{Bo}+\mathrm{Bi} \mathrm{Xi}$

$\mathrm{Pi}=\frac{1}{1+e^{-z i}}$. $1-\mathrm{Pi}=\frac{1}{1+e^{z}}$

The probability that a given household is rice production technology adopter is expressed in equation (2), while the probability for non-adopters of rice production technology is expressed in equation (3).

In this study, PSM was used to construct a group for comparisons based on probability model of adoption of rice cultivation technology. Members who adopted the technology are matched to non-adopters on the basis of the probability [or propensity scores, (PS)]. After matching the individuals with similar characteristics in both the adopter (treatment) and non-adopter (control) groups, the real effect of rice production technology adoption can then be calculated as the mean difference in rice output per hectare between the adopters and non-adopters. In addition to assessing the effect of adoption on rice output, the method of PSM allows us to examine the probability of a farmer adopting a technology. After estimating the propensity scores using the logit or probit model, the next task is to estimate an average treatment effect (ATE) of adoption on rice output. The ATE is estimated as the mean difference in rice output between adopters, denoted by Y (1) and matched control group, denoted by Y (0). Symbolically, equation (1) represents the model for estimation of the ATE.

$$
\mathrm{ATE}=\mathrm{E}[\mathrm{Y}(1) \mathrm{Y}(0)]=\mathrm{E}[\mathrm{Y}(1)] \mathrm{E}[\mathrm{Y}(0)]
$$

Where, ATE $=$ average total effect

$\mathrm{E}[\mathrm{Y}(1)=$ Average outcomes for individual, with treatment, if he/she would adopters $(\mathrm{Di}=1)$

$\mathrm{E}[\mathrm{Y}(0)=$ Average outcome of untreated, when he/she would non adopters, or absence of treatment $(\mathrm{Di}=0)$

The ATE model compares the rice output of farmers who adopted rice production technology with that of non-adopters or control for farmers that are similar in terms of observable characteristics and also partially control for non-random selection of participants in the rice production technology adoption program. The ATE as calculated in equation (1) could be interpreted as the effect of the rice production technology adoption on rice 
output. Apart from the ATE, an average treatment effect on the treated (ATT or ATET) is also estimated. The ATT model measures the effect of adoption on output for only farmers who actually adopted the rice production technology rather than across all rice farmers who could potentially adopt this technology. ATT is calculated using the expression in equation (2) as follows:

$$
\mathrm{ATT}=\mathrm{E}[\mathrm{Y}(1) \mathrm{Y}(0) \mathrm{D}=1]=\mathrm{E}[\mathrm{Y}(1) \mathrm{D}=1] \mathrm{E}[\mathrm{Y}(0) \mathrm{D}=1]
$$

Where $\mathrm{D}$ is a dummy or indicator for treatment $(\mathrm{D}=1$ for adopters, 0 for non-adopters). Again, one could also estimate the average treatment effect on the untreated or control groups (ATC), which measures what the effect of adoption on output would be for farmers who did not adopt the rice production technology at all. The model for measuring such a parameter is expressed by equation (3) below.

$$
\mathrm{ATC}=\mathrm{E}[\mathrm{Y}(1) \mathrm{Y}(0) \mathrm{D}=0]=\mathrm{E}[\mathrm{Y}(1) \mathrm{D}=0] \mathrm{E}[\mathrm{Y}(0) \mathrm{D}=0]
$$

According to Rosenbaum and Rubin (1983), the effectiveness of matching estimators as a feasible estimator for impact evaluation depends on two fundamental assumptions, namely:

Assumption 1: Conditional Independence Assumption (CIA):

It states that treatment assignment (Di) conditional on attributes, $\mathrm{X}$ is independent of the post program outcome [Y (1), Y (0)]. In formal notation, this assumption corresponds to:

$[\mathrm{Y}(1)-\mathrm{Y}(0)] \perp[\mathrm{D} \mid \mathrm{Xi}]$

This assumption imposes a restriction that choosing to participate in a program is purely random for similar individuals. As a consequence, this assumption excludes the familiar dependence between outcomes and participation that lead to a self-selection problem (Heckman et al, 1998).

\section{Assumption 2: Assumption of common support:}

$0<P(X)<1$

The assumption is that $\mathrm{P}(\mathrm{x})$ lies between 0 and 1 . This restriction implies that the test of the balancing property is performed only on the observations whose propensity score belongs to the common support region of the propensity score of treated and control groups (Becker et al., 2002). Individuals that fall outside the common support region were excluded in the treatment effect estimation. This is an important condition to guarantee improving the quality of the matching used to estimate the ATT.

The four commonly used matching algorithms, namely nearest neighbor matching, radius matching, caliper matching and kernel-based matching, has been employed to assess the impact of rice production technology on farmers' rice production.

\section{Results and Discussion}

\subsection{Socio-demographic Characteristics of the Respondents}

The study shows that about $30.89 \%$ of the sample households were headed by females and the remaining $69.11 \%$ were headed by males. In terms of adoption status for both adopter and non-adopter male households have more probability of adoption than female households. Non adopters' respondents said that, rice production technology adoption requires more labors, and it takes time and is not easy to access agricultural inputs.

Table 1: Sex of sample household head

\begin{tabular}{|l|l|l|l|l|}
\hline \multirow{2}{*}{ Sex } & \multicolumn{2}{|c|}{ Adopter } & \multicolumn{2}{c|}{ Non adopter } \\
\cline { 2 - 5 } & Frequency & $\%$ & Frequency & $\%$ \\
\hline Male & 66 & 34.55 & 66 & 34.55 \\
\hline Female & 25 & 13.09 & 34 & 17.80 \\
\hline Total & 91 & 47.65 & 100 & 52.35 \\
\hline
\end{tabular}

Pearson chi2 $(1)=0.9509 \operatorname{Pr}=0.329$,

Source: Own survey (2017)

The larger the farm size the farmer has, the better he/she is initiated to involve in adoption of rice production technology. Therefore, adopter households have more probability of adopting rice production technology than non-adopter households and family size of households is directly associated with adoption of rice production technology.

Table 2: Family size of sample household head

\begin{tabular}{|l|l|l|l|l|}
\hline Fshh & Mean & Minimum & Maximum & Total sample \\
\hline Adopter & 6.11 & 1 & 11 & 91 \\
\hline Non adopter & 5 & 1 & 9 & 100 \\
\hline
\end{tabular}

Pearson chi2 $(10)=52.8378 \quad \operatorname{Pr}=0.000$,

Sources: Own survey (2017)

The average labor force available was 3 man equivalents. The data result reveals that, the mean labor force participation is 3.07 with the minimum labor force participated is 1 and the maximum labor force participated is 7. About $47.64 \%$ of adopters and $52.36 \%$ of non-adopters have farm labor. 
Table 3: Participated labor force of sample household head

\begin{tabular}{|l|l|l|l|l|}
\hline Parlfor & Mean & Minimum & Maximum & Total \\
\hline Adopter & 3.07 & 1 & 7 & 91 \\
\hline Non adopter & 3.07 & 1 & 7 & 100 \\
\hline
\end{tabular}

Pearson chi2 (6) $=9.9472 \operatorname{Pr}=0.072$,

Source: Own survey (2017)

Definitely, education plays a great role in adoption of rice production technologies and other technologies. About $42.66 \%$ of the respondents were literates; this figure is greater than the national figure for adult literacy $(36 \%)$ indicating that the area is better off in terms of education.

Table 4: Education level of sample households head

\begin{tabular}{|l|l|l|l|l|}
\hline \multirow{2}{*}{ Eduhh } & \multicolumn{2}{|c|}{ Adopter } & \multicolumn{2}{c|}{ Non adopter } \\
\cline { 2 - 5 } & Frequency & $\%$ & Frequency & $\%$ \\
\hline Illiterate & 34 & 17.80 & 57 & 29.84 \\
\hline Primary & 31 & 16.23 & 28 & 14.66 \\
\hline Secondary & 26 & 13.61 & 15 & 7.85 \\
\hline Total & 91 & 47.65 & 100 & 53.35 \\
\hline
\end{tabular}

Pearson chi2 $(2)=8.5118 \quad \operatorname{Pr}=0.004$,

Source: Own survey (2017)

The landholding of the sample households ranges from 0.125 ha to 3 ha with an average figure of 1.066 hectares. The average livestock (including cattle, sheep, goats, pack animals, and poultry) was 4.46 TLU with the minimum and the maximum holdings of 0.7 TLU and 17.8 TLU respectively.

Table 1: Land and Livestock Ownership

\begin{tabular}{c|c|c|c}
\hline & Max & Min & Average \\
\hline Land (in hectare) & 3 & 0.125 & 1.066 \\
\hline Livestock (in TLU) & 17.8 & 0.7 & 4.46 \\
\hline
\end{tabular}

Source: Own Survey (2017)

Out of the total of adopters $37.17 \%$ of households were credit users while $10.47 \%$ did not want to take credit. And also showed that out of the total of non-adopters $29.84 \%$ of households were credit users while $22.51 \%$ did not want to take credit due to various reasons which are food consumptions rather than farm inputs consumption and unexpected expenditure, existing of high interest rate and by having enough money to buy agricultural inputs. About $67.02 \%$ had access to institutional credit.

Table 7: Credit user of sample household heads

\begin{tabular}{|l|l|l|l|l|}
\hline Use credits & Adopter & $\%$ & Non adopter & $\%$ \\
\hline User & 71 & 37.17 & 57 & 29.84 \\
\hline Non user & 20 & 10.47 & 43 & 22.51 \\
\hline Total & 91 & 47.65 & 100 & 52.35 \\
\hline
\end{tabular}

Pearson chi2 $(1)=9.5251 \operatorname{Pr}=0.432$,

Source: Own survey (2017)

About $27.75 \%$ of the adopter's sample household and $17.28 \%$ of non-adopters sample household get extension service around their villages while $19.90 \%$ of adopters sample household and $35.08 \%$ of non-adopters sample household did not get extension support respectively.

Table 8: Extension services user sample household heads

\begin{tabular}{|l|l|l|l|l|}
\hline Exten & Adopter & $\%$ & Non adopter & $\%$ \\
\hline Access & 53 & 27.75 & 33 & 17.28 \\
\hline Not access & 38 & 19.90 & 67 & 35.08 \\
\hline Total & 91 & 47.65 & 100 & 52.35 \\
\hline
\end{tabular}

Pearson chi2 $(1)=12.2638 \operatorname{Pr}=0.027$,

Source: Own survey (2017)

According to the data result $18.32 \%$ of adopters and about $17.28 \%$ of non-adopters were attending farmers training center while $29.32 \%$ of adopters and $35.08 \%$ of non-adopters were not attending farmers training at farmers training center because of the reason that their home is far from their farmers training center (FTC). About $64.4 \%$ of households did not get a chance to participate farmers training at farmers training and keeps them away from gaining best agricultural practices. 
Table 9: Attending of farmers training center of sample household head

\begin{tabular}{|l|l|l|l|l|}
\hline Atftc & Adopter & $\%$ & Non adopter & $\%$ \\
\hline Attained & 35 & 18.32 & 33 & 17.28 \\
\hline Not attained & 56 & 29.32 & 67 & 35.08 \\
\hline Total & 91 & 47.65 & 100 & 52.35 \\
\hline
\end{tabular}

Pearson chi2 $(1)=0.6199 \operatorname{Pr}=0.431$,

Source: Own survey (2017)

\subsection{The impact of technology adoption on rice production}

Estimating the propensity score is important for two things. The first one is to estimate the average treatment effect on the treated (ATT); and second, to obtain matched treated and non-treated farming households. According to Grilli, et al (2011), the necessary steps when implementing propensity score matching are: Propensity Score estimation, Choose matching algorithm, Check overlap/common support. Matching of adopter and non-adopter households were carried out to determine the common support region. The basic criterion for determining the common support region is to delete all observations whose propensity score is smaller than the minimum propensity scores of participants and larger than the maximum in the control group (Caliendo and Kopeining, 2008).

Table 1: Predict propensity score common support region

\begin{tabular}{|l|l|l|l|l|}
\hline Observations & Mean & Std. dev & Min & Max \\
\hline Adopters & 0.6616371 & 0,2408404 & 0.148124 & 0.9963699 \\
\hline Non-adopters & 0.3056574 & 0.2208784 & 0.150809 & 0.9759661 \\
\hline Total & 0.4752602 & 0.2909859 & 0.148124 & 0.9963699 \\
\hline
\end{tabular}

\section{Source: Own survey (2017)}

Accordingly, the common support region was satisfied in the range of 0.9759661 to 0.148124 by deleting 6 observations from those adopters only.

Table 2: pstest balance score matching

\begin{tabular}{r|c|c|c|c|c|c}
\hline \multicolumn{1}{l|}{ Matching } & \multicolumn{3}{|c|}{ Before Matching } & \multicolumn{3}{c}{ After Matching } \\
\hline Algorithm & Ps R & $\begin{array}{l}\text { LR chi } \\
\text { square }\end{array}$ & P-value & Ps R $^{2}$ & $\begin{array}{c}\text { LR chi } \\
\text { square }\end{array}$ & P-value \\
\hline Neighbor (1) & 0.313 & 82.64 & -000 & 0.024 & 5.70 & 0.969 \\
$(3)$ & 0.313 & 82.64 & -000 & 0.027 & 6.29 & 0.856 \\
$(5)$ & 0.313 & 82.64 & -000 & 0.021 & 5.06 & 0.708 \\
\hline Kernel (.1) & 0.313 & 82.64 & -000 & 0.032 & 7.51 & 0.875 \\
$(.25)$ & 0.313 & 82.64 & -000 & 0.023 & 5.37 & 0.191 \\
$(.5)$ & 0.313 & 82.64 & -000 & 0.071 & 16.32 & 0.000 \\
\hline Caliper (.1) & 0.313 & 82.64 & -000 & 0.024 & 5.70 & 0.969 \\
$(.25)$ & 0.313 & 82.64 & -000 & 0.04 & 5.70 & 0.969 \\
$(.5)$ & 0.313 & 82.64 & -000 & 0.024 & 5.70 & 0.969 \\
\hline Radius (.01) & 0.313 & 82.64 & -000 & 0.311 & 51.72 & 0.000 \\
$(.1)$ & 0.313 & 82.64 & -000 & 0.311 & 51.72 & 0.000 \\
$(.5)$ & 0.313 & 82.64 & -000 & 0.311 & 51.72 & 0.000 \\
\hline
\end{tabular}

\section{Source: own survey (2017)}

Table 2 showed the values of Pseudo R-square and LR chi-square before and after matching which can be used as indices for the fulfillment of the balancing requirement. The pseudo $R$-square indicates how well the regressors $X$ explain the participation probability, meaning all the explanatory (independent) important variables included in the model do exactly explains the probability of households rice production technology adoption. . After matching there should be no systematic differences in the distribution of covariates between both groups and therefore the pseudo R-square should be fairly low.

\section{Estimation of treatment effect: matching algorithms}

The choice of matching algorithm was carried out from nearest neighbor, radius, caliper and kernel methods. The choice of estimator based on three criteria; namely, balancing test, Pseudo R-square and matched sample size. The matching estimator which balances more independent variables, has low pseudo R-square value and results in large matched sample was chosen as being the best estimator of the data. Accordingly, nearest neighbor matching method with 5 was found to be the best estimator of the data of rice production (Table 2 and 3 ).

As depicted in the table, relatively, this estimator resulted in least pseudo R-square (0.021), large number of matched sample size (185) by discarding unmatched households from total of 191 households. And balancing test after matching percent of bias is below five percent and also its LR chi square is insignificant. Outcome variables 
are rice production which is measured in quintal per hectare.

The impact of adoption of rice production technology on household rice production was based on sample of matched treated and control groups, the estimated average treatment effect (ATT) significant effect on rice production of participant farmers with significant - statistic (3.48) at 1 percent significance level $(\mathrm{p}<0.001)$. The average production of rice crop of adopters of rice production technology household was higher by 9.48 quintal per hectare in a given product year when compared with the average production of non-adopter households.

Table 3: Propensity score, NN matching, kernel matching, caliper matching and radius matching results

\begin{tabular}{|c|c|c|c|c|c|c|}
\hline Outcome variable & Algorithm & $\begin{array}{l}\text { Number } \\
\text { adopter }\end{array}$ & $\begin{array}{l}\text { Number of non- } \\
\text { adopter }\end{array}$ & ATT & $\mathrm{SE}$ & $\begin{array}{l}\text { t- } \\
\text { value }\end{array}$ \\
\hline \multirow{11}{*}{$\begin{array}{l}\text { Rice production in quintal } \\
\text { per hectare }\end{array}$} & \multirow{3}{*}{$\begin{array}{r}\text { Neighbor }(1) \\
(3) \\
(5)\end{array}$} & 85 & 100 & 9.07 & 2.96 & 3.06 \\
\hline & & 85 & 100 & 9.64 & 2.49 & 3.87 \\
\hline & & 85 & 100 & 9.48 & 2.72 & 3.48 \\
\hline & \multirow{3}{*}{$\begin{array}{ll}\text { Kernel } & (.01) \\
& (.25) \\
& (.5) \\
\end{array}$} & 85 & 100 & 6.72 & 2.35 & 2.86 \\
\hline & & 85 & 100 & 9.85 & 2.27 & 4.32 \\
\hline & & 85 & 100 & 9.21 & 2.02 & 4.56 \\
\hline & \multirow{3}{*}{$\begin{array}{l}(.01) \\
(.1) \\
(.25)\end{array}$} & 85 & 100 & 6.40 & 2.48 & 2.58 \\
\hline & & 85 & 100 & 9.07 & 2.96 & 3.06 \\
\hline & & 85 & 100 & 9.07 & 2.96 & 3.06 \\
\hline & \multirow{2}{*}{$\begin{array}{l}(.01) \\
(.1)\end{array}$} & 85 & 100 & 9.96 & 1.63 & 6.08 \\
\hline & & 85 & 100 & 9.96 & 1.63 & 6.08 \\
\hline
\end{tabular}

\section{Source: Own survey (2017)}

\section{Sensitivity test for average treatment effect on the treated}

Sensitivity analysis is a strong identifying assumption and must be justified. According to (Grilli and Rampichini, 2011) sensitivity analysis is the final diagnostic that must be performed to check the sensitivity of the estimated treatment effect to small changes in the specification of the propensity score. As table 4 below shows the concept of the sensitivity analysis that the significance level is unaffected even if the gamma values are relaxed in any desirable level even up to $100 \%$ percent. This shows that average treatment effect on treated is not sensitive to external change. Hence there are no external variables which affect the result above calculated for ATT result.

\section{Table 4: Sensitivity test of external effect on ATT}

\begin{tabular}{|c|c|c|c|c|}
\hline Gamma & Q-mh+ & Q-mh- & P-mh+ & P-MH- \\
\hline 1 & 12.2069 & 12.2069 & 0 & 0 \\
\hline 1.05 & 12.0948 & 12.4007 & 0 & 0 \\
\hline 1.1 & 11.9516 & 12.5493 & 0 & 0 \\
\hline 1.15 & 11.8164 & 12.693 & 0 & 0 \\
\hline 1.2 & 11.6885 & 12.8321 & 0 & 0 \\
\hline 1.25 & 11.567 & 12.9671 & 0 & 0 \\
\hline 1.3 & 11.4515 & 13.0981 & 0 & 0 \\
\hline 1.35 & 11.3415 & 13.2255 & 0 & 0 \\
\hline 1.4 & 11.2365 & 13.3494 & 0 & 0 \\
\hline 1.45 & 11.136 & 13.4702 & 0 & 0 \\
\hline 1.5 & 11.0399 & 13.5879 & 0 & 0 \\
\hline \multicolumn{5}{|c|}{$\begin{array}{l}\text { NB. Gamma : odds of differential assignment due to unobserved factors } \\
\text { Q_mh+ : Mantel-Haenszel statistic (assumption: overestimation of treatment effect) } \\
\text { Q_mh-: Mantel-Haenszel statistic (assumption: underestimation of treatment effect) } \\
\text { p_mh+ : significance level (assumption: overestimation of treatment effect) } \\
\text { p_mh-: significance level (assumption: underestimation of treatment effect) }\end{array}$} \\
\hline
\end{tabular}

Sources: Own survey (2017)

\section{Conclusion and Recommendation}

This study tried to assess the contribution of rice production technology adoption on rice production by using propensity score matching method which helps in separating the true impact of adoption of rice production technology. The study employed cross sectional household level data collected in 2016/2017 cropping season from 191 sample farming households. A propensity score matching approach was used to compare adopter households with non-adopters in terms of their rice production levels as measured in quintal per hectare. The results show that rice production technology had a robust and positive impact on farmers' rice production levels.

The implication of the findings is straight forward; even if the adoption of rice production technology is quite low in Fogera Woreda, those households who could use the technology could improve their production. It is better 
to encourage rice technology adoption because the results of this study signified that application of rice production technology increase the production of adopters. Based on the key findings of this study the study recommended that adopting rice production technology as a package (row and spacing, improved seed, fertilizer rates and or compost, early hand weeding and hoeing, tilling repeatedly) is vital as a policy in enhancing rice yield on the marginal farm lands. Complementary agricultural technology adoption best yield results when they are taken up as a complete package together, rather than in the individual elements to give high rice yield.

\section{Reference}

[1]. Abdulai A, Huffman WE (2005) The diffusion of new agricultural technology: The case of Cross-bred cow technology in Tanzania. Am. J. Agric. Econ. P 87.

[2]. Adekambi, S. A., A. Diagne, F. P. Simtowe, and G. Biaou (2009) The Impact of Agricultural Technology Adoption on Poverty: The Case Of, NERICA Rice Varieties in Benin. Contributed paper prepared for presentation at the International Association of Agricultural Economists' conference, Beijing, China, August 16.-22, 200.

[3]. Bola AA, Aliou D, Omonona BT (2012). Impact of improved agricultural technology adoption on sustainable Rice production and Rural Farmers "e welfare in Nigeria: A local Average Treatment Effect (ATE) Technique.

[4]. Caliendo M. and Kopeinig S (2008) some practical guidance for the implementation of propensity score matching Journal of Economic Surveys, Vol. 22, No. 1, pp. 3172.

[5]. CIMMYT (1993) The Adoption of Agricultural Technology: A Guide for Survey.

[6]. Diagne A, Adekambi SA, Simtowe FP and Biaou G (2009) Impact of agricultural technology adoption on poverty: The case of NERICA rice varieties in. Paper presented at the 27 th . Conference of the International Association of Agricultural Economists, Beijing. Benin.

[7]. Dontsop-Nguezet, P.M, A. Diagne, V.O.Okoruwa and V.E.T. Ojehomon. (2011). Impact of Improved Rice Technology Adoption (NERICA varieties) on Income and Poverty among Rice Farming Households in Nigeria: A Local Average Treatment Effect (LATE) Approach. QuarterlyJournal of International Agriculture 50(2011), no.3:2.

[8]. FAO (2010) Rice Market Monitor. Food and Agriculture Organization of the United Nations. Volume XVIIssue No.1.

[9]. Graaff, J.d., A. Kessler, J.W. Nibbering (2011) Nibbering Agriculture and Food Security in selected countries in Sub-Saharan Africa: diversity in trends and opportunities. Food Security 3:195-213.

[10].Grilli, Leonardo, and Carla Rampichini ( 2011) Propensity scores for the estimation of average treatment effects in observational studies.46P.

[11]. Kijima Y, Otsuka K and Sserunkuuma D (2008) Assessing the impact of NERICA on income and poverty in central and western Uganda. Agricultural Economics38:327-337.

[12].Mendola (2007) Agricultural technology Adoption and poverty reduction: A propensity score matching Analysis for rural Bangladesh.University of Milano,Milano Italy.

[13]. Rosenbaum, P.R., and Rubin, D.B (1983) The Central Roleof the Propensity Score in Observational Studies for Causal Effects. Biometric, 70 (1): 41-55.

[14].Setotaw Ferede,Gezahegn Ayele And Hailemariam Teklewold (2003) Impact Of Tecvhnology On Households Food Security In Tef And Wheat Farming Systems ofMoretnaJiruworeda. Ethiopian Agricultural Research Organization (EARO), Research Report No.48.

[15].Solomon Asfaw, Bekele Shiferaw and Franklin Simtowe (2010) Does Technology Adoption Promote Commercialization? Evidence from Chickpea Technology in Ethiopia.

[16]. Tsegaye M, Bekele H (2012) Impacts of Adoption of Improved Wheat Technology on Households ${ }^{\text {ee }}$ Food Consumption in Southeastern Ethiopia.

[17]. Wanyama, J. M., Nyambati, E. M., Mose, L. O, Mutoko, C. M, Wanyonyi, W. M. Wanjekeche, E. and Rono, S. C (2010) Assessing impact of soil management technology on smallholder farmers' livelihoods in North Western Kenya. . African Journal of Agricultural Research 5(21):2899-2908.

[18]. World Bank (2008) Agriculture Development Report 2008: Agriculture for Development.The World Bank. Washington, DC, USA.

[19].Wu, H., S. Ding, S. Pandey and D. Tao (2010) Assessing the Impact of Agricultural Technology Adoption on Farmers’ Well-Being In Rural China. Asian Economic Journal 24 (2): , 141-160. 